University of Nebraska - Lincoln

DigitalCommons@University of Nebraska - Lincoln

1988

\title{
Effects of Gender, Ethnicity, and School Equity on Students' Leadership Behaviors in a Group Game
}

Helen A. Moore

hmoore1@unl.edu

Follow this and additional works at: https://digitalcommons.unl.edu/sociologyfacpub

Part of the Gender and Sexuality Commons, Inequality and Stratification Commons, and the Race and Ethnicity Commons

Moore, Helen A., "Effects of Gender, Ethnicity, and School Equity on Students' Leadership Behaviors in a Group Game" (1988). Sociology Department, Faculty Publications. 99.

https://digitalcommons.unl.edu/sociologyfacpub/99

This Article is brought to you for free and open access by the Sociology, Department of at DigitalCommons@University of Nebraska - Lincoln. It has been accepted for inclusion in Sociology Department, Faculty Publications by an authorized administrator of DigitalCommons@University of Nebraska - Lincoln. 
Effects of Gender, Ethnicity, and School Equity on Students' Leadership Behaviors in a Group Game

\author{
Helen A. Moore \\ University of Nebraska-Lincoln
}

The Elementary School Journal

Volume 88, Number 5

(C) 1988 by The University of Chicago. All rights reserved. 0013-5984/88/8805-0006\$01.00

\begin{abstract}
Leadership skills and the perception of leadership by students and classroom teachers are examined in 10 desegregated elementary schools. The 10 schools were first divided into "high-equity" and "low-equity" schools based on the extent to which they met "integrative" educational criteria, such as multicultural curricula, multiethnic staff, minority parent involvement, and other factors. A random sample of 202 Hispanic and Anglo students participated in a cooperative group task in gender-segregated groups composed of 3 students from each ethnic group. Results indicate that trained observers found gender differences in nonverbal and verbal leadership behaviors among students across the schools, including higher activity rates overall in the high-equity schools. Observers did not find ethnic or gender differences in global leadership scores. Teachers and students rated Hispanic students lower on leadership, and this difference was most marked for Hispanic females in low-equity schools. The article includes a discussion of variation in school desegregation effects, as well as school and community leadership roles for Hispanics.
\end{abstract}

Issues of ethnic and racial educational equity and school desegregation programs have been a center of controversy in public education for the past 30 years. Gender has more recently entered the arena as a focal point of questions about equity and outcomes. Educational completion rates for Mexican-American students have lagged behind those for blacks and Anglos for both high school and college (Moore, 1976). Today, the median educational level for all Hispanics is 11 years, well below the 12.6 average for the U.S. population (U.S. Bureau of the Census, 1985, p. 134). MexicanAmerican women complete high school and college at rates even below their male peers (Carter \& Segura, 1979). 


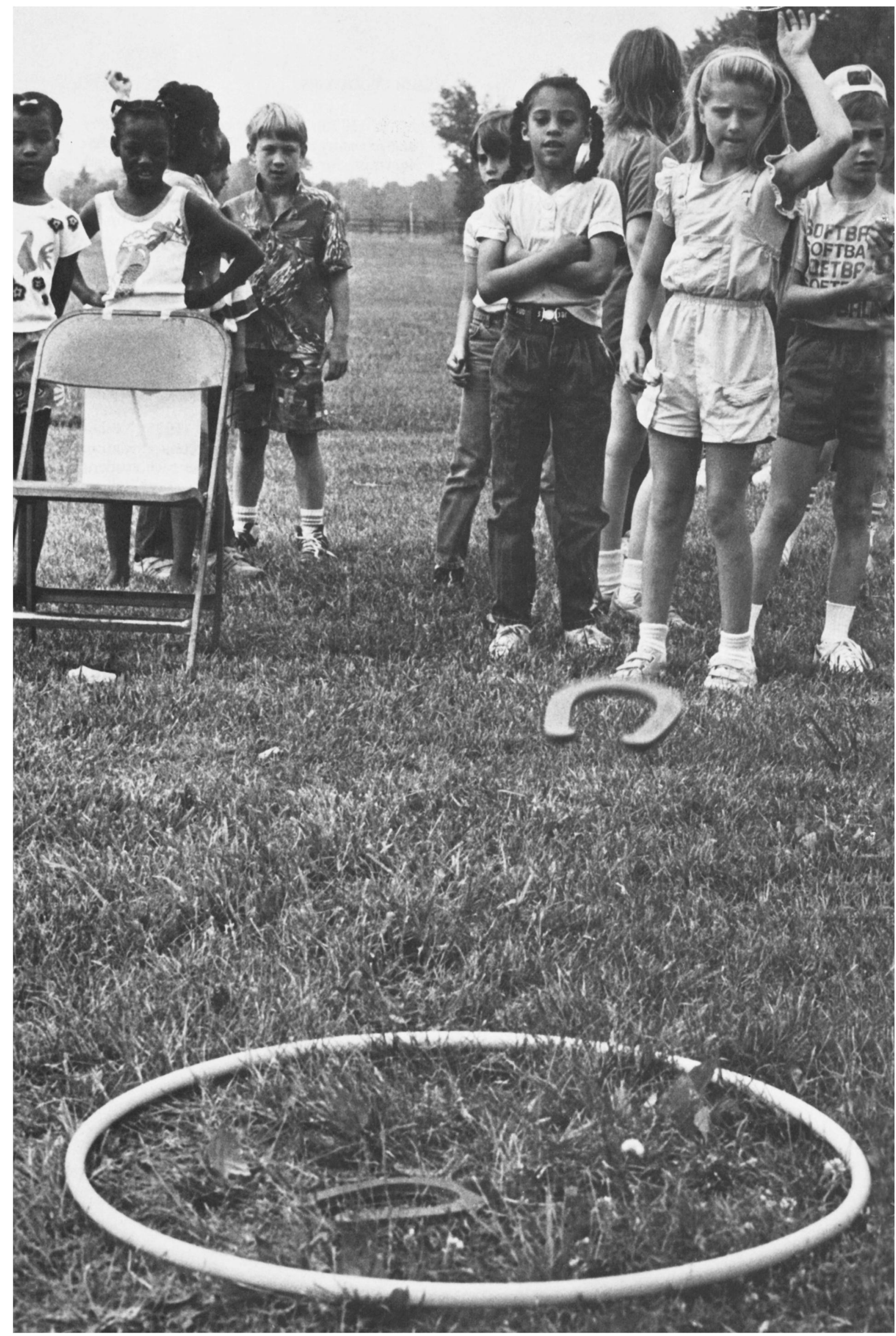


In the past, relationships among ethnicity, gender, and educational outcomes have been overlooked or oversimplified in rhetoric and research. Both research and school programs were based on the belief that contact between lower-class minority children and higher-achieving white students would benefit not only minority students' academic performance but also their social integration and social skills (St. John, 1975).

More recently, researchers have studied school desegregation processes (see Mercer, Iadicola, \& Moore, 1980) and the complexity of social processes related to integration, students' interracial behavior (Cohen, 1984), and gender differences in skills that are reinforced in the schools (Deem, 1982). These schooling processes are profoundly affected by the gender and ethnicity of the students, teachers, and administrators involved. Public schools transmit hierarchical arrangements of status through formal and informal curricula, academic skills, and social behaviors such as leadership (Bowles \& Gintis, 1976; Grant, 1984; Iadicola \& Moore, 1983).

This article outlines a theory and describes a study of Hispanic and Anglo students' leadership behaviors and perceptions of leadership in 10 desegregated schools. It also focuses on differential leadership ratings of males and females by their classroom teachers and trained observers. Researchers and revisionist theorists such as Bowles, Gintis, and Deem have developed the analytic tools to identify institutionalized patterns of ethnic cultural dominance as well as characteristics of gendered culture that might affect these student outcomes. This article examines more carefully the effects of school equity on student leadership behaviors and outcomes. A high-equity desegregated school that provides multicultural teachers, curricula, and interaction opportunities may foster leadership among ethnic minority and female students.

\section{Hispanics in the schools}

Revisionist historians have argued that group educational inequities are linked to cultural biases favoring Anglo-Saxon linguistic and behavioral norms in the schools (Carlson, 1975). These norms are apparent in English language dominance in classroom instruction and testing but extend to other normative dimensions of schooling: "The school seeks to develop independence, competitiveness and self-assertiveness, while Chicano culture emphasizes cooperation, respect and obedience to elders. These qualities are especially valued in females" (Mirande \& Enriquez, 1979, p. 132). To MexicanAmericans who value linguistic and cultural autonomy, education in the United States presents a singular threat of assimilation (Acuna, 1981).

In addition to cultural exclusion, the schools recapitulate segregation in the larger society through segregation of students into schools and internal school programs by ethnicity and social class. Mexican-American students historically have been segregated de facto from Anglo students and resources. At times, some Mexican-American groups claimed Caucasian identity to gain access to segregated school systems, making segregation a double-edged cultural sword (Weinberg, 1983). Educational administrators used Hispanic students as functional substitutes for Anglos in response to court reviews of segregation. For example, in the 1960s, Texas accepted desegregation plans that integrated only blacks and Chicanos (Scimecca, 1980).

The educational segregation of Hispanic students was not formally recognized until 2 decades after the Brown v. Topeka Board of Education decision, when Mexican-Americans organized politically around issues of racial segregation (Acuna, 1981). Nationwide, the number of students attending intensely segregated schools-those with $90 \%$ or more minority enrollment-has risen from $28.8 \%$ in 1980 to $31 \%$ in 1984 .

During the past 15 years, Hispanic communities have assessed the potential effects of school desegregation on bilingual education, community control, and achievement of Hispanic students. Community or- 
ganizations have questioned the dispersal of bilingual and community-based educational programs, assessing the cultural costs associated with desegregation and busing (San Miguel, 1982). Similarly, they have analyzed allocation of local school revenues that often advantage Anglo-dominated districts and schools (Acuna, 1981). School desegregation thus creates a particularly complex set of potential benefits and costs to the Hispanic community.

\section{The desegregated school environment}

The social organization of schools according to gender and ethnicity reflects stratification in the larger society. It includes segregated gender and ethnic patterns among teaching and support staff (Weinberg, 1983); the dominance of English language, history, and norms within the curriculum; the use of certain teaching styles (Ramirez \& Castaneda, 1974); and diminished expectations among teachers and students for minority students' performance inside and outside of the classroom (Weinberg, 1983).

\section{Desegregation outcomes}

Cautious claims have been made about potential positive effects of school desegregation for Hispanic students. Generally, research indicates that minority students' academic achievement is marginally improved, although self-esteem and other social-psychological characteristics improve (St. John, 1975). Cross-race contact and communication are enhanced under certain school desegregation conditions (Damico \& Sparks, 1986). However, other analyses indicate that minority females may be placed at a disadvantage in desegregated classrooms. Grant (1984) found that black females were encouraged to enhance social skills instead of academic skills, to act as "go-betweens" for other students. Her qualitative analysis examined the helping relationships, peer networks, and physical interactions of desegregated first graders. In a quantitative study of desegregated elementary schools, Moore (1983) found that Hispanic females were positively evaluated by teachers for passive, docile classroom behaviors, whereas their Anglo peers were encouraged to take active educational and social roles. These studies suggest that a student's gender and ethnicity may influence perceptions and behaviors of the teachers and peers in the desegregated school.

Gandara (1982) found that high-achieving Mexican-American women had attended disproportionately more "highly-integrated" schools. For most, "school was a source of interaction with the majority culture and an opportunity to test their abilities against an objective standard" (Gandara, 1982 , p. 177). We might well quarrel with the "objective" standards for leadership and achievement that are defined by Anglo and male-dominated institutions, but Gandara's research indicates that successful interaction within such environments may lead to higher achievement among Chicanas.

One complicating factor in assessing desegregation is the research model frequently used to study school effects. The complex process of school desegregation is often treated in policy and research as dichotomous: a particular school that contains a minimum number, or "tipping point," of minority students is defined as desegregated; if it does not, it is labeled as segregated. Too often, variation in desegregation among schools is not taken into account because of restricted research funds or inadequate organizational and educational information. The definition of a desegregated school posited in this article is more accurately the definition of an "integrated" school environment: a school that moves beyond numerical mixing of students to explicit attempts to have staff and curriculum reflect the diversity of students' racial and ethnic backgrounds (Allport, 1954).

Metz's (1986) organizational analysis of three magnet schools shows discernible differences in outcomes of integration across desegregated schools. This research is qualitatively rich and includes considerable discussion of variations among desegregated 
school structures in technological arrangements, district policy, faculty culture, and administrative factors. These factors were interdependent. Essentially, Metz found a subculture in two of the three schools in which faculty made efforts to gain knowledge of their students, both cognitively and emotionally, and emphasized positive dimensions of their relations with students. This subculture affected teachers' understanding of district and administrative directives, determined their actions toward students in verbal and nonverbal exchanges, and conveyed teacher expectations for students that "are crucial in determining the experience of students," including more positive interracial relationships.

Grant (1983) examined gender differences for black students across desegregated elementary school classrooms. Overall, girls showed less social power in interchanges with boys; instead, girls took on more "supporter/caretaker" roles. Majority-black classrooms appeared to be more genderequal than classrooms dominated numerically by whites. These qualitative studies by Metz and Grant suggest that contextual variations among desegregated schools should be taken into account when researching gender and ethnic differences in student behaviors.

\section{Integration and contact theory}

Factors that promote integration and elevate minority students' status have been identified in the last decade. Desegregated schools that provide group versus individual student evaluations, multiethnic staff, parent involvement, integrated academic and extracurricular opportunities, multicultural curricula and that equitably distribute the burden of busing among students generally have better academic and social outcomes for minority students (Johnson, Johnson, Tiffany, \& Zaidman, 1983; Mercer et al., 1980; Rosenholtz \& Cohen, 1983).

Contact theory identifies a series of situation-specific conditions in which minority ethnicity and gender become less salient fac- tors in outcomes of schooling. Included among these conditions are cooperative interdependence among students and support from administration and staff (Allport, 1954), as well as a supportive curriculum, breakdown of stereotypic beliefs, and encouragement of acquaintanceship (Damico \& Sparks, 1986).

Early schooling is the setting for many Hispanic students' first cultural clashes with Anglo language, norms, interaction styles, and definitions of "success." Schools also reinforce gendered societal expectations for appropriate goals, skills, and behaviors of male and female students (Grant \& Sleeter, 1986; Moore, 1983; Vasquez, 1982). Racism and/or sexism may be challenged to varying degrees within schools, either by the explicit policies of administrators or teachers' classroom practices (Grant \& Sleeter, 1986).

The general theme in this article is that "high-equity" schools-schools that incorporate a range of practices that diminish ethnic and gender stratification-can enhance minority students' skills and the positive perception of minority students' skills by peers and teachers. This article argues that in subtle ways, the leadership of Hispanics and females is enhanced by a school environment that integrates as opposed to merely desegregates.

\section{Issues in defining leadership}

Leadership in school settings is a complex concept. As Conoley $(1980$, p. 35) points out, "leadership is a construct central to education. . . . What is it? Who has it? How do we get it?" Schools provide multiple opportunities for leadership: student government, student organizations, scholastic and classroom activities, organized athletics, and informal playground and lunchroom interactions. Clusters of student roles and behaviors may shift between formal and informal settings, across activities, and within teacherand student-dominated settings.

The behavioral definition of leadership in most school research is derived from taskoriented groups, and these groups likely re- 
flect the dominant norms of Anglo and male groups. From the educational and psychological focus on small task groups, a leader has come to be defined as the person who has group support and who influences the group toward his or her preferences without exerting external authority (Shaw, 1971). Past research has focused on individuals' traits and personality characteristics and attributes leadership to these variables (Conoley, 1980 , p. 36).

Leadership is also associated in the larger society with gender, ethnicity, and specific clusters of skills. Males and Anglos are more likely to be identified as having "leadership" qualities (Pearson, 1985). From studies of adults, we know that verbal and nonverbal skills are associated with perceptions of leadership in general. There is also evidence that students' academic self-concepts, academic ability, and social power are related to their perceptions of themselves as leaders (Rosenholtz \& Simpson, 1984).

\section{Verbal skills}

A wide range of verbal skills are highly associated with leadership in studies of adults. Individuals perceived as leaders tend to talk more and to interrupt more (Henley, 1977). Bernstein (1973) and Vasquez (1972) suggest that language resources, particularly English language skills, are related to perceptions of "ability" and evaluations of minority students in educational settings. Baratz and Baratz (1970) and Rosenfeld (1973) hypothesize that language mediates between students' ethnicity and their teachers' expectations and evaluations.

Luis Lausa (1977) replicated earlier research on teacher expectations and found that teachers generally viewed MexicanAmerican elementary students less positively than Anglo students. Language dominance of the students (English vs. Spanish) was the most salient influence on teacher approval. Spanish-dominant Mexican-American students experienced increasingly negative teacher reactions between kindergarten and second grade. Results were similar for males and females.

\section{Nonverbal skills}

Several nonverbal behaviors have been shown to be associated with leadership and status within adult groups. Individuals thought of as leaders tend to occupy more central seating positions in a group setting, yield their positions less often, and physically elevate themselves above others in a group (Schwartz, Tesser, \& Powell, 1982). Individuals with higher status are also likely to use more personal space and more often touch others and intrude into others' personal space (Mehrabian, 1971).

These nonverbal behaviors are learned and tend to vary with social status, ethnic background, and gender (Mayo \& Henley, 1981). Among adults, males are generally more dominant and display a range of nonverbal leadership behaviors, including more dominance of personal space (wider gestures, more gestures, stretching of arms and legs, open body position) and intrusions and touching of others (see Henley, 1977, and Pearson, 1985, for a review of this literature).

Aiello and Jones (1971) found both gender and ethnic differences in nonverbal behaviors among first- and second-grade students. Middle-class Anglos stood farther apart than black and Hispanic students, and this was most apparent among Anglo males. The authors conclude that these nonverbal behaviors are acquired early in life and demonstrate significant differences between dominant groups (Anglos and males) and minority culture in the use of space. Jones (1971) found that females in each ethnic group stood closer together than did their male peers.

\section{Leadership issues for Hispanic and female students}

Leadership quite likely takes different forms in different settings, depending on available leadership positions, the task of the group, the cooperative/competitive mix of 
group goals, and the gender and ethnic composition of the group. Lockheed (1976) demonstrated that leadership among sixthgrade females is suppressed by the mere presence of male peers, even when one has enhanced female skills. This pattern also appears among Hispanic females in classroom settings with Hispanic males (Garcia-Bahne, 1978). When considering a multiethnic, multicultural educational setting, the supportive nature of the environment is critical to the identification and exertion of leadership (Garza, Romero, Cox, \& Ramirez, 1982). Supportive group conditions will significantly increase Hispanic leadership in small groups, though the exact nature of the behaviors related to leadership and group support is unexamined at this point.

Little research has been conducted on Hispanic females' leadership behavior. For women and minorities in school settings, the definition of leadership style is complex, but in general it incorporates some of the following dimensions: group-oriented or egalitarian; self-oriented or authoritarian; participatory or permissive; and observing or supervisory. Little is known about the objective behaviors of Hispanic female students within group settings. We also know little about the perceptions of those around Hispanic females-the community, teachers, parents, and peers-and their acceptance or rejection of leadership by Hispanic females.

Berezaulce-Mulcahy (1980) discusses the leadership roles of adult Latinas in the context of bilingual education. She argues that Latinas are accorded special opportunities for leadership in education because it is identified as a "woman's field." Education is associated with children, and women are "responsible" for matters pertaining to children. Berezaulce-Mulcahy also emphasizes that consciousness-raising educational activities by Hispanic females have focused on the Latino community in general as opposed to identity awareness among women per se.

Lopez (1977) describes social factors in the dominant Anglo community and the Chicano community that constrained the leadership of Chicanas in the high school and college student movements of the 1960s and 1970s. In addition to racism on the part of educational administrators, Chicanas faced restrictive gender expectations within activist groups. Lopez concluded that Chicanas were caught in a double bind, although they provided skills and leadership within the movement. It is crucial that we gain more understanding of the effects of school structure on the early development of leadership skills among Hispanic students.

\section{Method}

\section{Subjects}

The participants in this investigation were 202 elementary students (third and sixth grade) from 10 desegregated schools in California. Equal numbers of male and female, Anglo and Hispanic students were randomly selected. All of the Hispanics were MexicanAmerican. The 10 schools were selected from an earlier study of student outcomes in 182 desegregated schools. Rank orders of the standardized residual scores on measures of academic outcomes, self-esteem, cross-ethnic friendship choices, and other mental health indicators were calculated, controlling for grade level, school political environment, and socioeconomic and ethnic composition (Iadicola, Lewis, Moore, \& Nickles, 1978). Five of the schools with high educational and self-esteem outcomes for Hispanic students, and five with low outcomes, agreed to participate in a further case study. This school sample exhibited the widest variance in school outcomes of the 182 schools in the original sample.

\section{Procedure}

Information on the school environment was collected from administrators, student records, faculty and other staff surveys, parent interviews, and observations of students. Information on individual students was obtained from classroom teachers, parents, student questionnaires, parent interviews, and videotaped interactions among the stu- 
dents that were later coded by trained personnel. In the following analyses, we assess how student leadership behavior varies by gender, ethnicity, and school equity environment (high or low). In earlier analyses, we found that the high- and low-equity schools differed significantly in patterns of multicultural staffing, curriculum, parent involvement, burden of busing on minority students, testing, and ability grouping (Iadicola \& Moore, 1983). The high-equity schools had educational programs consistent with models for positive integration and interracial contact.

In the present analysis, we include only the five high- and five low-equity schools. We omit social class background of the student. An earlier analysis of leadership scores coded by observers and teachers showed no significant variation by student social class (Iadicola \& Moore, 1983). However, variations in school social class composition were associated with differences in leadership scores for Anglos and Hispanics in these schools.

Thirty-five groups of Hispanic and Anglo students were videotaped while playing a cooperative group game, "Space Station Pegasus." Each group contained six children of the same grade and gender, three Anglos and three Hispanics. We used gender-homogeneous groups to observe and code leadership behaviors in environments where leadership opportunities were equally available to males and females. The game was played outside of the classroom. Students were provided with a table, a set of supply cards depicting survival items (oxygen tanks, food, etc.), and a narrated scenario about a stranded lunar crew. Students first selected one of six crew positions for themselves and other game players ranging from deckhand to medical officer to commander. Students then ranked the supply cards individually, and finally ranked the cards as a group. The group interaction was audio- and videotaped (see Iadicola \& Moore, 1983, for a detailed description of the game procedures).

The videotapes were coded three times by trained male and female staff from three ethnic groups, two black, two Hispanic, and two Anglo of each gender. Coders were randomly assigned to rate students across groups and seating positions. In 1978, the tapes were coded for leadership factors, using a semantic differential (Iadicola \& Moore, 1983). In 1984-1985, a new group of staff, again equally representative of gender and ethnicity, coded a series of specific verbal and nonverbal leadership behaviors.

Leadership ratings. We wanted to compare the perceptions of student leadership among students, teachers, and multiethnic observers. Observers rated each of the students on 11 semantic differential pairs that described global leadership qualities in students (e.g., follows/initiates, effective/ineffective). Half of the items were reversed in scoring to avoid response sets. The reliability among coders was .97. Teachers completed similar leadership ratings on all students in their classrooms using adjective pairs. Reliability for the teacher scale was .93 (see Iadicola \& Moore, 1983, for factor loadings and scale items on both observer and teacher leadership ratings). At the end of the game, students were asked to vote for the student in their small group who most influenced the game, and a cumulative index of votes was created.

Leadership behaviors. The following items were coded three times, each by a randomly assigned coder (Cronbach's alpha of reliability is given in parentheses following each item): number of physical intrusions, including touching and hitting others (.67); number of verbal interruptions directed at others (.72); number of seconds using upward vertical space, including standing up during the game (.85); seconds using more than one-sixth of the game table in horizontal space (.86); seconds of self-comforting behavior (.76); seconds speaking (.87); and seconds touching the resource cards (.81). Each student was assigned the mean of the scores given by three raters.

The total average group interaction time varied significantly between male ( $3 \mathrm{~min}, 33$ sec) and female groups ( $3 \mathrm{~min}, 58 \mathrm{sec})$. To 
control for these group differences, the students' individual behavior scores were divided by their overall group time to obtain a weighted factor that was used in subsequent analyses.

\section{Results}

\section{Leadership behaviors and school equity}

The average raw and weighted scores for all students on the leadership behaviors show that students did not vary by grade level but varied significantly by ethnicity within gender groups. Ethnic-group mean scores were tested with a Scheffé analysis of variance procedure within gender groups. Hispanic males were more likely than Anglo males to control the resource cards, while Anglo males used more combined physical space (upward and horizontal expansion) and verbal interruptions (see Table 1). These verbal differences were more pronounced in the lowequity schools, with Anglo males scoring significantly higher $(\phi<.05)$ on both verbal interruptions and speaking time.

Hispanic females were significantly less likely than Anglo females $(p<.05)$ to use upward movement, verbal interruptions, expanded personal space, and even self-comforting behaviors (see Table 2). Anglo females in both high- and low-equity schools were more likely than Hispanic females $(\phi$ $<.05$ ) to use verbal interruptions. Only in high-equity schools did Anglo females have significantly higher speaking time scores than Hispanic females, but scores for both Anglo and Hispanic females were lower in the lowequity schools. Hispanic females were more likely than their Anglo peers to use the resource cards in the low-equity schools (as were the Hispanic males), perhaps to balance the verbal interruptions of Anglos.

When we compared overall behavior rates for students in high-equity schools to students in low-equity schools, we found that some, but not all, of these leadership activities vary. Students in high-equity schools had significantly greater rates $(p<.05)$ of verbal interruption and upward and horizontal movement. Their rates of physical intrusion and use of resource cards were also higher, though the differences were not significant. Hispanic males and females maintained their control of the resource cards in the low-equity schools, while Anglo scores dropped in these schools. Students in high-equity schools showed lower rates of self-comforting behaviors. Overall, the high-equity schools seem to provide a more active interaction environment, with higher scores on those factors associated with leadership among adults, though this varies by gender and ethnicity. Hispanic females' activity rates were higher in the high-equity schools (especially in terms of upward and horizontal movement), but in low-equity schools they used

TABle 1. Average Leadership Behavior Scores for Male Anglo and Hispanic Students in High- and Low-Equity Schools

\begin{tabular}{|c|c|c|c|c|}
\hline & \multicolumn{4}{|c|}{ School Equity } \\
\hline & \multicolumn{2}{|c|}{ High-Equity } & \multicolumn{2}{|c|}{ Low-Equity } \\
\hline & Anglo & Hispanic & Anglo & Hispanic \\
\hline Physical intrusion & 1.83 & 1.99 & 1.62 & 1.68 \\
\hline Verbal interruption & 1.98 & $1.67 *$ & 1.58 & $1.27 *$ \\
\hline Upward movement & 12.49 & 11.09 & 5.97 & $4.57^{*}$ \\
\hline Horizontal movement & 40.15 & 38.92 & 30.10 & 28.87* \\
\hline Self-comfort & 9.72 & 9.46 & 11.07 & 10.81 \\
\hline Speaking time & 13.55 & 13.74 & 16.10 & $12.24^{*}$ \\
\hline Resource cards & 23.80 & $27.78^{*}$ & 16.65 & $28.86^{*}$ \\
\hline
\end{tabular}

*Significant at $p<.05$. Scheffé test for analysis of variance in ethnic-group mean scores. 
TABLE 2. Leadership Behavior Scores for Female Anglo and Hispanic Students in High- and Low-Equity Schools

\begin{tabular}{|c|c|c|c|c|}
\hline & \multicolumn{4}{|c|}{ School Equity } \\
\hline & \multicolumn{2}{|c|}{ High-Equity } & \multicolumn{2}{|c|}{ Low-Equity } \\
\hline & Anglo & Hispanic & Anglo & Hispanic \\
\hline Physical intrusion & 1.34 & 1.50 & 1.13 & 1.29 \\
\hline Verbal interruption & 1.71 & $1.40^{*}$ & 1.31 & $1.00^{*}$ \\
\hline Upward movement & 11.49 & 10.09 & 4.97 & $3.57 *$ \\
\hline Horizontal movement & 34.99 & 34.26 & 25.44 & $24.21 *$ \\
\hline Self-comfort & 3.61 & $3.35^{*}$ & 4.96 & $4.70^{*}$ \\
\hline Speaking time & 15.62 & $11.78^{*}$ & 11.18 & 13.08 \\
\hline Resource cards & 20.00 & 22.14 & 14.55 & $19.67 *$ \\
\hline
\end{tabular}

*Significant at $p<.05$. Scheffé test for analysis of variance in ethnic-group mean scores.

game cards as a significant leadership resource.

\section{Perceptions of leadership}

Table 3 shows that the trained observers did not assign significantly different overall leadership scores to students, either by ethnicity or school equity. A separate analysis indicated that observers' ratings were related primarily to students' verbal skills and speaking time in the group (Moore \& Porter, in press). Observers knew nothing of the students' social or academic standing within a school.

Teachers' and students' perceptions of student leadership, however, were signifi- cantly related to school equity. Students in low-equity schools consistently voted more often that Anglo students had the most influence on the game than did students in high-equity schools. These differences are statistically significant $(p<.01)$ for Anglo females (with a mean score of 1.08) and Hispanic females (mean score of 0.62 ) in the low-equity schools. Separate analyses (see Moore \& Porter, in press) indicated that students' ratings of male and female leadership were most affected by speaking time, verbal skills, academic GPA, and student pregame ranking (what crew position they were assigned at the beginning of the game). Females' leadership ratings by other students

TABLE 3. Leadership Ratings for Students in High- and Low-Equity Schools

\begin{tabular}{|c|c|c|c|c|}
\hline & \multicolumn{4}{|c|}{ School Equity } \\
\hline & \multicolumn{2}{|c|}{ High-Equity } & \multicolumn{2}{|c|}{ Low-Equity } \\
\hline & Anglo & Hispanic & Anglo & Hispanic \\
\hline \multicolumn{5}{|l|}{ Observer ratings: } \\
\hline Male students & 47.93 & 46.27 & 45.72 & 44.32 \\
\hline Female students & 46.83 & 46.01 & 46.42 & 44.72 \\
\hline \multicolumn{5}{|l|}{ Student votes: } \\
\hline Male students & 1.08 & 1.01 & 1.03 & .99 \\
\hline Female students & 1.13 & .95 & 1.08 & $.62 *$ \\
\hline \multicolumn{5}{|l|}{ Teacher ratings: } \\
\hline Male students & 19.83 & 17.43 & 18.76 & 16.98 \\
\hline Female students & 23.95 & 21.72 & 20.72 & $18.25^{*}$ \\
\hline
\end{tabular}

*Significant at $p<.05$. Scheffé analysis of variance for ethnic-group mean scores. 
were significantly influenced by school equity $(p<.01)$. Female Hispanics in low-equity schools received lower leadership ratings than their counterparts in high-equity schools, even when other academic and skill factors were controlled.

Teachers' ratings yielded a similar pattern. Teachers generally gave Anglo students and female students the highest leadership ratings. Separate analyses showed that teachers' ratings were related to students' English Word Knowledge test scores and school equity (Moore \& Porter, in press). Students in high-equity schools received higher leadership scores overall. However, Hispanic females in the low-equity schools received lower leadership scores than Hispanic males when compared to all students with similar academic records and skills. Leadership scores for males were not significantly different for Anglos and Hispanics, once other factors were controlled.

It is interesting that teachers' ratings were only marginally correlated with observations of trained staff $(r=.186, p<.05)$. Although teachers did not see the cooperative interaction game, neither did the observers see the students in their classrooms. Teachers' ratings were more closely related to students' ratings $(r=.310, p<.001)$. Evidently, the school environment strongly influenced the teachers' ratings of global leadership and the votes of student peers, even though trained observers assigned global leadership scores across school environments without reference to ethnicity.

\section{Discussion}

Variation in school equity appears to influence the expression and perception of leadership by Hispanic students and their teachers. The statistical analyses presented in this article are essentially descriptive, but show strong patterns of differentiation across the 10 elementary schools. They support the notion that high-equity schools provide a more supportive environment for expression and recognition of leadership among Hispanic males and females.
Both Hispanic and Anglo males and females in high-equity schools showed higher rates of interaction during the game than students in low-equity schools. Students in high-equity schools engaged in more expansive movements, both horizontal and vertical; used more verbal interruptions; used physical intrusion; and touched the resource cards for longer periods of time. This was true for males and females of both ethnic groups. Overall, observers reported higher physical activity rates for students in highequity schools, indicating more animated involvement in the cooperative group task. These schools seem to provide a lively arena for trying out a range of leadership behaviors.

Interestingly, the observers identified similar rates of global leadership across types of students and schools. Considering that the sample included an equal number of students from high- and low-equity schools and an equal number of potential leadership positions within groups, one would expect an equivalent number of students at each type of school to move into group leadership roles. However, observers reported no significant differences in the perceived leadership of Anglo or Hispanic students in either male or female groups.

Teacher and student perceptions were more a reflection of equity environments of schools. Teachers generally ranked Anglo students higher in leadership than Hispanics. However, teachers in high-equity schools assigned Hispanic male and female students higher leadership scores than did teachers in low-equity schools, even after controlling for students' academic background. Overall, teachers perceived females as having greater leadership skills than males in general, although, again, teachers did not observe the gender-segregated groups. Students voted for the most influential members in the group interaction, and they, too, were likely to view Hispanic students in the high-equity schools more favorably. Although both males and females showed this trend, female students in the high-equity schools had more 
positive evaluations of Hispanic females' leadership.

Our larger study, and other research (Garza et al., 1982; Grant, 1983; Metz, 1986), indicate that high-equity schools are associated with multicultural role models, cooperative educational goals, less tracking, more parental involvement, and higher rates of academic success for minority students. One point should be noted. High- and lowequity schools varied in student social class, with high-equity schools having a higher school SES. Evidently, school socioeconomic composition had a powerful influence on teachers' and peers' perceptions of students' leadership, although observers' scores were unaffected. This analysis does not assess accurately these effects, which should be investigated further.

A high-equity environment in a desegregated school can affect student leadership in a variety of ways. First, it provides a setting in which male and female students approach tasks with a wider range of leadership behaviors. Additionally, students and teachers in high-equity schools recognize the leadership contributions of Hispanic males and females.

The single-sex groups used in this study do not reflect actual conditions in the coeducational public school. Considering the attention that high-equity schools give to curricular and role model issues related to ethnicity, it is likely that these schools also provide more equitable leadership opportunities for males and females than do lowequity schools. Clearly, this must be tested in studies of coeducational school activities.

Finally, this study does not wholly address the issue of various definitions of leadership. Hispanic community definitions of leadership and leadership by Hispanic men and women in different settings require more study. Male and female Anglo and Hispanic students are socialized to some extent by adults' verbal and nonverbal leadership behaviors. High-equity, integrated educational environments apparently make the leadership skills of Hispanic females and males more evident to peers and teachers. The support of leadership behaviors and the perception of leadership of diverse students are complex but important components of successful integration in desegregated schools.

Note

Portions of this research were funded by NIMH Public Health Research grant no. MH 26607-03 and from a coauthored grant with $\mathrm{Na}$ talie K. Porter from the University of Nebraska, Lincoln, Faculty Research Council. I would like to express my appreciation to Linda Grant for her helpful comments and patient editing on an earlier draft of this paper.

\section{References}

Acuna, R. (1981). Occupied America: A history of Chicanos (2d ed.). New York: Harper \& Row.

Aiello, J. R., \& Jones, S. E. (1971). Field study of the proxemic behavior of young school children in three subcultural groups. Journal of Personality and Social Psychology, 19, 351-356.

Allport, G. (1954). The nature of prejudice. Reading, MA: Addison-Wesley.

Baratz, S. S., \& Baratz, J. C. (1970). Early educational intervention: The social science base of institutional racism. Harvard Educational Review, 40, 29-50.

Berezaulce-Mulcahy, E. (1980). Latinas in educational leadership: Chicago, Illinois. In National Institute of Education Conference on the educational and occupational needs of Hispanic women (pp. 75-86). Washington, DC: National Institute of Education.

Bernstein, B. (1973). Social class, language and socialisation. Current Trends in Linguistics, 12 , 473-486.

Bowles, S., \& Gintis, H. (1976). Schooling in capitalist America. New York: Basic.

Carlson, R. (1975). The quest for conformity: Americanization through education. New York: Wiley.

Carter, T. P., \& Segura, R. D. (1979). MexicanAmericans in school: $A$ decade of change. New York: College Entrance Board.

Cohen, E. G. (1984). The desegregated school: Problems in status, power and interethnic climate. In N. Miller \& M. Brewer (Eds.), Groups in contact: The psychology of desegregation (pp. 77-95). New York: Academic Press. 
Conoley, J. C. (1980). The psychology of leadership: Implications for women. In S. R. Biklen \&c M. B. Brannigan (Eds.), Women and educational leadership (pp. 35-48). Lexington, MA: Heath.

Damico, S. B., \& Sparks, C. (1986). Cross-group contact opportunities: Impact on interpersonal relationships in desegregated middle schools. Sociology of Education, 59, 113-123.

Deem, R. (1982). Women and schooling. New York: Routledge \& Kegan Paul.

Gandara, P. (1982). Passing through the eye of the needle: High-achieving Chicanas. Hispanic Journal of Behavioral Sciences, 4, 167179.

Garcia-Bahne, B. (1978). La Chicana and the Chicano family. In R. Sanchez \& R. Cruz (Eds.), Essays on la mujer (pp. 30-47). Los Angeles: Chicano Studies Publication Center.

Garza, R. T., Romero, G. J., Cox, B. G., \& Ramirez, M., III. (1982). Biculturalism, locus of control and leader behavior in ethnically mixed groups. Journal of Applied Social Psychology, 12, 237-253.

Grant, C. A., \& Sleeter, C. E. (1986). After the school bell rings. Philadelphia: Falmer.

Grant, L. (1983). Gender roles and status in school children's peer interactions. Western Sociological Review, 14, 58-76.

Grant, L. (1984). Black females' "place" in desegregated classrooms. Sociology of Education, 57, 98-110.

Henley, N. M. (1977). Body politics. Englewood Cliffs, NJ: Prentice-Hall.

Iadicola, P., Lewis, J., Moore, H., \& Nickles, H. (1978). Study of effective multiethnic schools technical manual. Riverside, CA: PRIME.

Iadicola, P., \& Moore, H. (1983). The desegregated school and status relations among Anglo and Hispanic students: The dilemma of school desegregation. Aztlan: International Journal of Chicano Studies, 14, 39-58.

Johnson, D. W., Johnson, R., Tiffany, M., \& Zaidman, B. (1983). Are low achievers disliked in a cooperative situation? A test of rival theories in a mixed ethnic situation. Contemporary Educational Psychology, 8, 189-200.

Jones, S. E. (1971). A comparative proxemics of dyadic interaction in selected sub-cultures of New York City. Joumal of Social Psychology, 84, 35-44.

Lausa, L. (1977). Inequality in the classroom: Observational research on student-teacher interactions. Aztlan: International Journal of Chicano Studies, 8, 51-68.

Lockheed, M. E. (1976). The modification of female leadership behavior in the presence of males. Princeton, NJ: Educational Testing Service (PR 76-28).
Lopez, S. (1977). The role of the Chicana within the student movement. In R. Sanchez \& R. Cruz (Eds.), Essays on la mujer (pp. 16-30). Los Angeles: University of California Press.

Mayo, C., \& Henley, N. (1981). Gender and nonverbal behavior. New York: Springer-Verlag.

Mehrabian, A. (1971). Verbal and nonverbal interaction of strangers in a waiting situation. Journal of Experimental Research in Education, 5, 127-138.

Mercer, J., Iadicola, P., \& Moore, H. (1980). Building effective multiethnic schools: Evolving models and paradigms. In W. G. Stephan \& J. R. Feagin (Eds.), School desegregation: Past, present, and future (pp. 281-304). New York: Plenum.

Metz, M. H. (1986). Different by design: The context and character of three magnet schools. New York: Routledge \& Kegan Paul.

Mirande, A., \& Enriquez, E. (1979). La Chicana: The Mexican-American woman. Chicago: University of Chicago Press.

Moore, H. A. (1983). Hispanic females: Schooling for conformity in public education. Hispanic Journal of Behavioral Sciences, 5, 45-63.

Moore, H. A., \& Porter, N. (in press). Leadership and nonverbal behaviors of Hispanic females across school equity environments. Psychology of Women Quarterly.

Moore, J. (1976). Mexican Americans (2d ed.). Englewood Cliffs, NJ: Prentice-Hall.

Pearson, J. C. (1985). Gender and communication. Dubuque, IA: Brown.

Ramirez, M., III, \& Castaneda, A. (1974). Cultural democracy, bicognitive development and education. New York: Academic Press.

Rosenfeld, L. B. (1973). An investigation of teachers' stereotyping behavior. Albuquerque: New Mexico University. (ERIC Document Reproduction Service No. ED 090 172)

Rosenholtz, S. J., \& Cohen, E. G. (1983). Back to basics and the desegregated school. Elementary School Journal, 83, 515-527.

Rosenholtz, S. J., \& Simpson, C. (1984). Classroom organization and student stratification. Elementary School Journal, 85, 21-37.

San Miguel, G. Jr. (1982). Mexican-American organizations and the changing politics of school desegregation in Texas. Social Science Quarterly, 63, 701-715.

Schwartz, B., Tesser, A., \& Powell, E. (1982). Dominance cues in nonverbal behavior. Social Psychology Quarterly, 45, 114-120.

Scimecca, J. A. (1980). Education and society. New York: Holt, Rinehart \& Winston.

Shaw, M. E. (1971). Group dynamics: The psychology of small-group behavior. New York: McGraw-Hill. 
St. John, N. S. (1975). School desegregation: Outcomes for children. New York: Wiley.

U.S. Bureau of the Census. (1985). Statistical $a b$ stract of the United States. Washington, DC: Government Printing Office.

Vasquez, J. (1972). Measurement of intelligence and language differences. Aztlan: International Journal of Chicano Studies, 3, 155-163.
Vasquez, M. J. T. (1982). Confronting barriers to the participation of Mexican-American women in higher education. Hispanic Journal of $\mathrm{Be}$ havioral Sciences, 4, 147-165.

Weinberg, M. (1983). The search for quality integrated education Westport, CT: Greenwood. 